\title{
Geologia
}

\section{O Maciço Alcalino de Tunas, PR: Novos Dados Geocronológicos}

\author{
Oswaldo Siga Júnior? (osigair@usp.br), Celso de Barros Gomes', Kei Sato², Cláudia Regina Passarelli² \\ 'Departamento de Mineralogia e Geotectônica - Instituto de Geociências - USP \\ R. do Lago 562, CEP 05508-080, São Paulo, SP, BRA \\ ${ }^{2}$ Centro de Pesquisas Geocronológicas - Instituto de Geociências - USP, São Paulo, SP, BRA
}

Recebido em 26 de abril de 2007; aceito em 31 de julho de 2007

Palavras-chave: geocronologia, magmatismo alcalino, maciço alcalino de Tunas.

\section{RESUMO}

A intrusão de Tunas, de forma alongada para NW-SE e ocupando área de $22 \mathrm{~km}^{2}$, ocorre a aproximadamente $80 \mathrm{~km}$ da cidade de Curitiba e está encaixada em terrenos metavulcanossedimentares pré-cambrianos do Grupo Açungui. Cinco estruturas vulcânicas de contorno subcircular são reconhecidas. Do ponto de vista petrográfico, o maciço consiste principalmente em sienitos e álcali sienitos, com presença subordinada de gabros alcalinos, essexitos, sienogabros e sienodioritos; pequenos diques, de formação tardia e natureza sienítica, e brechas magmáticas estão também presentes. Idades K-Ar obtidas anteriormente (valor médio de 82,2 Ma) indicam que as rochas de Tunas são do Cretáceo Superior. Neste trabalho são apresentadas novas determinações, utilizando-se do método U-Pb em cristais de zircão de rochas sieníticas (ID-TIMS, 82,7 $\pm 0,7 \mathrm{Ma}$; SHRIMP, 84,7 $\pm 1,2 \mathrm{Ma}$ ),que confirmam essa idade e permitem colocar Tunas no grupo de intrusões alcalinas do Cretáceo Superior associadas tectonicamente com o Lineamento São Jerônimo-Curiúva, uma feição estrutural ligada ao Arco de Ponta Grossa, de orientação NW-SE, na região Sudeste do Brasil.

Keywords: geochronology, alkaline magmatism, alkaline Tunas massif.

\section{ABSTRACT}

The NW-SE elongated Tunas intrusion, occupying an area of $22 \mathrm{~km}^{2}$, crops out about $80 \mathrm{~km}$ from the city of Curitiba, and it is emplaced into Precambrian metavolcanic-sedimentary rocks of the Açungui Group. Five sub-circular volcanic structures are recognized. Petrographically, the massif mainly consists of syenites and alkali syenites with subordinate alkali gabbros, essexites, syenogabbros and syenodiorites; small late syenitic dykes and magmatic breccias are also found. Previous K-Ar data give a Late Cretaceous mean age of $82.2 \mathrm{Ma}$ for Tunas rocks. In this article we present new U-Pb age determinations on zircon crystals from syenitic rocks (ID-TIMS, $82.7 \pm 0.7 \mathrm{Ma}$; SHRIMP, $84.7 \pm 1.2 \mathrm{Ma}$ ) which confirm that age, placing the massif into the Late Cretaceous group of alkaline intrusions tectonically associated with the São Jerônimo-Curiúva Lineament, a NW-SE-trending branch of the Ponta Grossa Arch in southern Brazil. 


\section{INTRODUÇÃO}

A intrusão de Tunas, ao lado de outras ocorrências alcalinas encontradas na divisa dos Estados do Paraná e São Paulo, está enquadrada na Província de Tunas (Ulbrich e Gomes, 1981) ou, segundo entendimento de maior aceitação, na Província do Arco de Ponta Grossa (Almeida, 1983). Ruberti et al. (2005) procuram incluí-la no agrupamento que reúne corpos intrusivos maiores (Banhadão, Barra do Itapirapuã, Itapirapuã, Mato Preto), plugs (Barra do Ponta Grossa, Barra do Teixeira, Sete Quedas) e diques (Cerro Azul, Morro do Chapéu, estrada Sete Quedas-Dr. Ulisses) associados tectonicamente ao Lineamento São Jerônimo-Curiúva. Este representa um dos quatro sistemas de falhas (Rio Piquiri, Rio Alonso; São Jerônimo-Curiúva e Guapiara, cf. Figura 1) integrantes da grande feição estrutural referida como Arco de Ponta Grossa (Almeida, 1986). Ativo provavelmente desde os tempos paleozóicos, estendendo-se por quase $600 \mathrm{~km}$ e mergulhando para o interior da Bacia do Paraná, o arco tem orientação geral NW e se dispõe perpendicularmente às estruturas NE do embasamento do Ciclo Brasiliano. Ele responde também pela formação de fraturas tensionais de direção NW, preenchidas por enxames de diques de rochas basálticas toleíticas, que mostram maior concentração na região de influência do Lineamento Guapiara, ainda que estejam presentes nas demais áreas. Esse lineamento é responsável pelo condicionamento tectônico dos importantes complexos alcalinos de Jacupiranga e Juquiá, além dos corpos de Pariquera-Açu, Cananéia, Ipanema, Piedade e Tatuí (Ruberti et al., 2005).

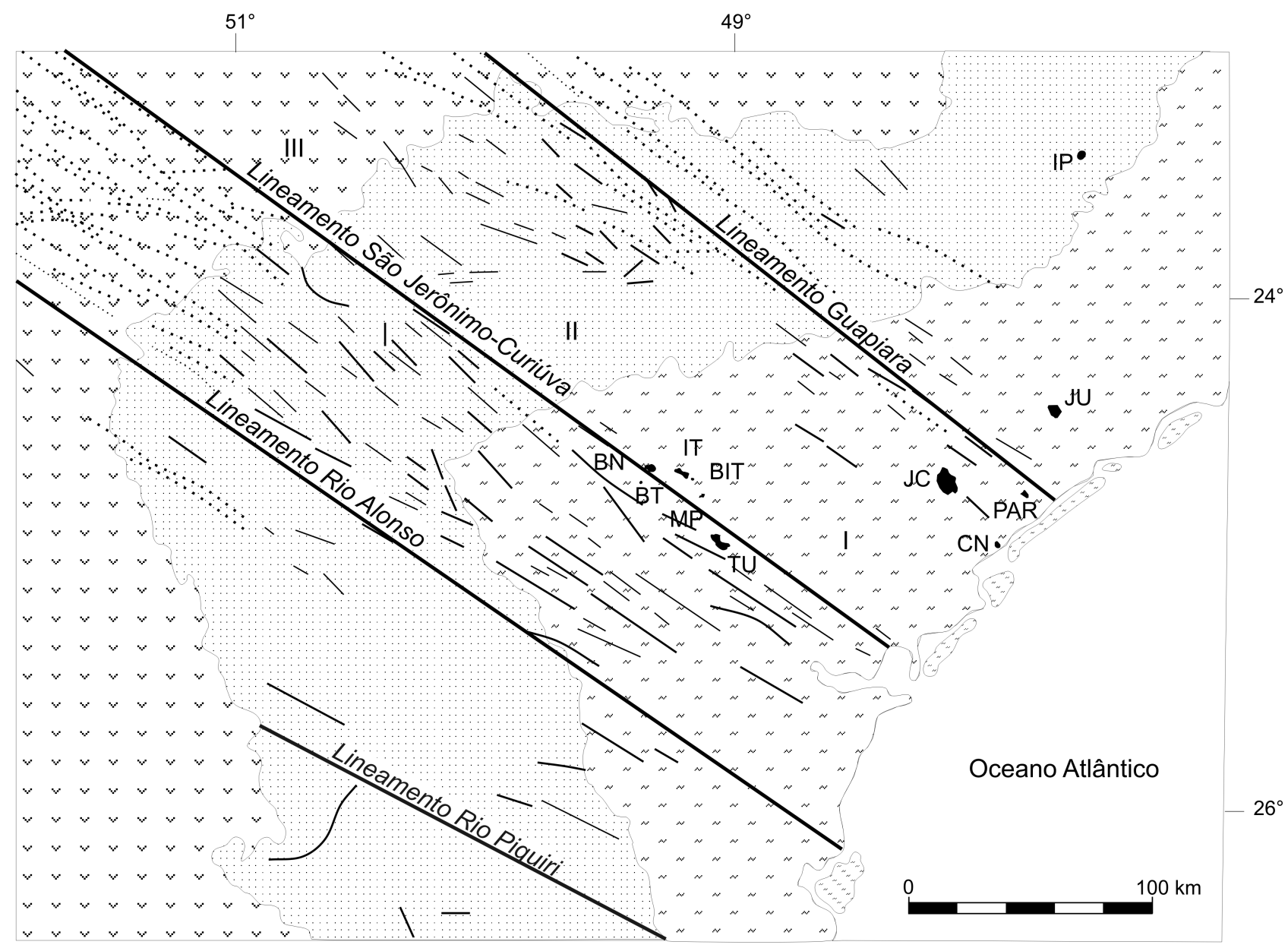

Figura 1. Condicionamento tectônico do magmatismo alcalino mesozóico no Arco de Ponta Grossa (cf. Almeida, 1986; simplificado de Ruberti et al., 2005). Os enxames de diques NW-SE são inferidos por geologia de campo, sensoreamento remoto e levantamento aeromagnético. As principais intrusões alcalinas estão indicadas como se segue: BIT = Barra do Itapirapuã, BN = Banhadão, BT = Barra do Teixeira, CN = Cananéia, IP = Ipanema, IT = Itapirapuã, JC = Jacupiranga, $\mathbf{J U}=$ Juquiá, $\mathbf{M P}=$ Mato Preto, $\mathbf{P A R}=$ Pariquera-Açu, $\mathbf{T U}=$ Tunas. Outras representações: $\mathbf{I}=$ embasamento cristalino, II = rochas sedimentares da Bacia do Paraná, III = rochas basálticas toleíticas da Formação Serra Geral. 
Por outro lado, Riccomini et al. (2005), o magmatismo alcalino na Província do Arco de Ponta Grossa seria representado tão-só pelas ocorrências do Cretáceo Inferior. Aqui estão incluídos os dois complexos referidos acima e, ainda, o de Anitápolis, em Santa Catarina, o qual não mostra qualquer controle estrutural mais evidente, ao contrário dos demais fortemente influenciados pela tectônica NW-SE. Nesse trabalho é também sugerida a extensão da área de influência do Arco de Ponta Grossa, de modo a incluir, em direção ao sul, a ocorrência catarinense e, para nordeste, as intrusões de Ipanema, Itanhaém e Piedade. Como resultado desse novo modelo de distribuição, desaparecem as províncias de Santa Catarina e de Ipanema propostas anteriormente por Almeida (1983). Ainda com base em idades radiométricas $\mathrm{K} / \mathrm{Ar}$ disponíveis na literatura, Riccomini et al. (2005) admitiram para as rochas do Cretáceo Inferior uma subdivisão em dois conjuntos: um mais antigo, reunindo as ocorrências de Jacupiranga e Juquiá, que dispõem de análises mais confiáveis e em maior número, e um mais novo, exemplificado pelas intrusões de Itapirapuã (Gomes e Cordani, 1965) e Tunas (Gomes et al., 1987).

Por outro lado, os corpos alcalinos reconhecidamente do Cretáceo Superior, como Cananéia (Amaral et al., 1967; Sonoki e Garda, 1988; Spinelli et al., 2001), Barra do Teixeira e Mato Preto (Amaral et al., 1967; Sonoki e Garda, 1988), ainda que dentro da área geográfica do Arco de Ponta Grossa, foram incluídas por Riccomini et al. (2005) dentro do chamado "setor central" da Província da Serra do Mar, enquanto o complexo de Lages (integrando a então Província de Santa Catarina de Almeida, 1983) colocado junto ao seu "setor meridional".

Com o objetivo de melhor caracterizar épocas relacionadas à formação das rochas sieníticas do Maciço de Tunas são, neste trabalho, apresentadas novas determinações radiométricas utilizando-se do método U-Pb (ID-TIMS e SHRIMP) em cristais de zircão.

\section{SITUAÇÃO GEOLÓGICA}

O maciço de Tunas, distante cerca de $80 \mathrm{~km}$ da cidade de Curitiba, apresenta forma alongada segundo NW-SE e cobre área aproximada de $22 \mathrm{~km}^{2}$ (Figura 2). Morfologicamente, compreende cinco estruturas subvulcânicas de contorno anelar, e encontra-se encaixado em terrenos metavulcanossedimentares pré-cambrianos do Grupo Açungui. O maciço foi investigado primeiramente por Trein et al. (1967) e, de forma mais minuciosa, por Fuck (1972), com apresentação de mapa geológico e descrição dos principais tipos petrográficos existentes. Anos mais tarde ele voltaria a ser objeto de pesquisa, com Gomes et al. (1987) tratando, sobretudo, dos seus aspectos petrológicos e geoquímicos.

Do ponto de vista petrográfico, o maciço é de natureza sienítica, consistindo essencialmente em sienitos e álcali sienitos, com presença menor de quartzo álcali sienitos (tipo pulaskítico). Rochas sienodioríticas ocorrem de forma subordinada, concentrando-se principalmente na porção noroeste da intrusão, enquanto variedades de afinidade mais gábrica excluídos alguns pequenos afloramentos de natureza mais sienogábrica e essexítica (álcali gabros) formam um pequeno stock junto à sua borda oriental. Pequenos e raros diques existentes mostram também composição sienítica (microssienitos com textura traquítica e bostonítica). Brechas vulcânicas de formação tardia estão presentes especialmente nas partes noroeste e central do maciço.

Feldspatos (feldspato alcalino e plagiocásios, estes últimos mais freqüentes nos tipos petrográficos de afinidade gábrica, onde mostram composição variável de bytownita a oligoclásio), clinopiroxênios (Ti-salita passando a ferrosalita e egirina-augita), anfibólios (de natureza essencialmente pargasítica), micas (ferro-biotita ocasionalmente enriquecida em Ti), olivinas (hortonolita a ferro-hortonolita), quartzo e feldspatóides (presentes em alguns sienitos e essexitos e representados por nefelina, sodalita e cancrinita) são os principais minerais das rochas de Tunas, enquanto opacos (Ti-magnetita e ilmenita exsolvida) e apatita constituem os acessórios mais comuns.

\section{GEOCRONOLOGIA}

\section{Métodos Isotópicos}

Os estudos isotópicos do maciço foram realizados no Centro de Pesquisas Geocronológicas (CPGeo) do Instituto de Geociências da Universidade de São Paulo (U-Pb, zircão: TIMS; Sm-Nd: $\mathrm{T}_{\mathrm{DM}}$ ) e nos laboratórios da Research School of Earth Sciences, Australian National University, Canberra (U-Pb: SHRIMP). O programa de pesquisa envolveu rochas sieníticas e microssieníticas, estas últimas ocorrendo na forma de diques em meio às seqüências metavulcanossedimentares pré-cambrianas do Grupo Açungui.

\section{Análises U-Pb (ID-TIMS)}

A obtenção de concentrados de zircão para análises $\mathrm{U}-\mathrm{Pb}$ foi feita utilizando-se britador de mandíbulas, moinho de discos, conjunto de peneiras, mesa de Wiffley, separador magnético tipo Frantz e líquidos densos (bromofórmio e iodeto de metileno). A seleção fina (multigrãos) foi realizada manualmente com o auxílio de lupa binocular, usando-se para pesagem a relação densidade $v s$. volume. Foram selecionados para análise cerca de 10 a 15 cristais de zircão, que, após submetidos a trabalho de limpeza com $\mathrm{HCl}+\mathrm{HNO}_{3}$, foram dissolvidos em micro-bombas de teflon, sendo o urânio $(\mathrm{U})$ e o chumbo $(\mathrm{Pb})$ separados por meio de colunas de resina anionica, segundo procedimentos descritos em Basei 


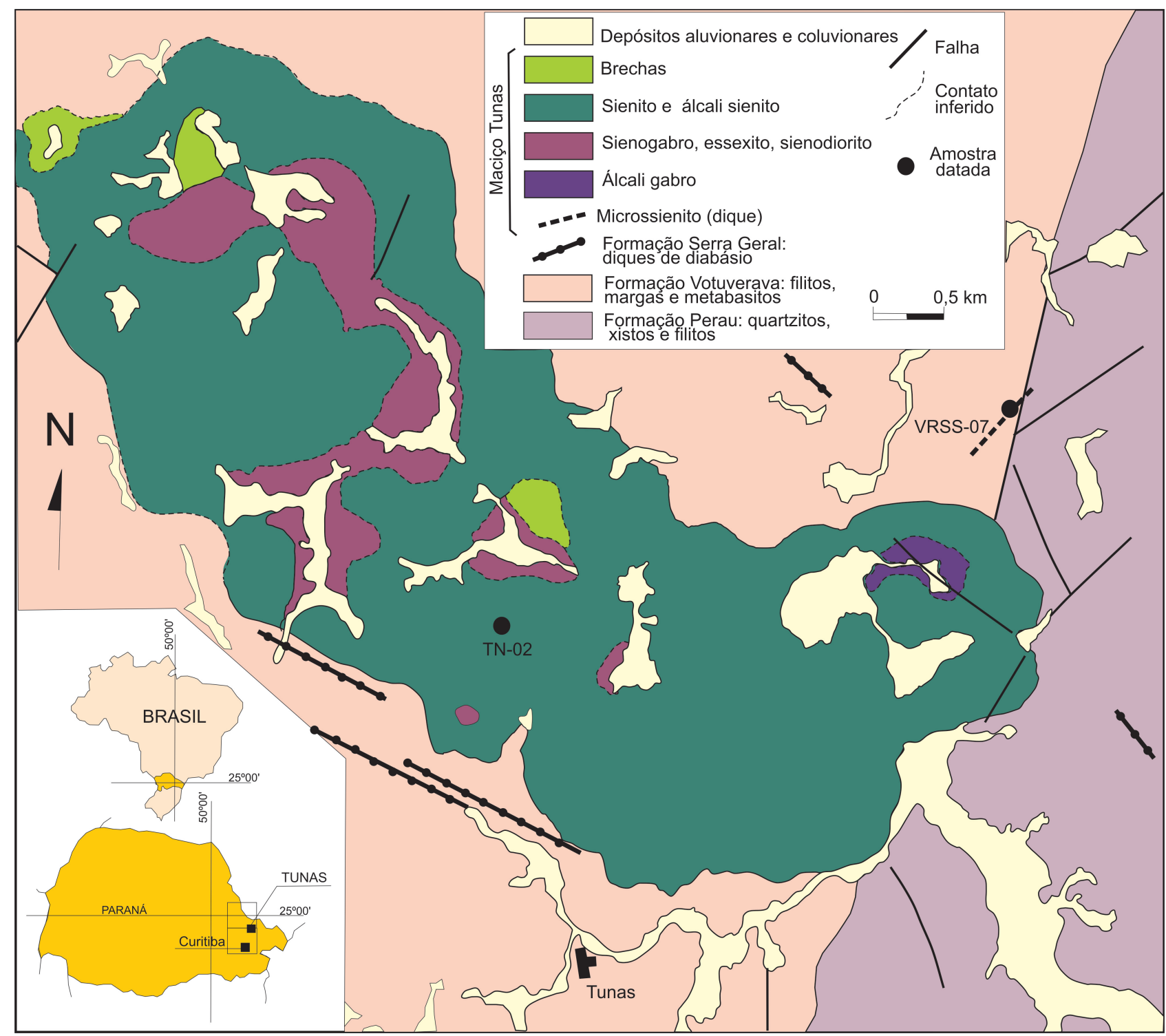

Figura 2. Mapa geológico do maciço alcalino de Tunas (simplificado de Fuck, 1972) mostrando a localização das amostras investigadas.

et al. (1995), adaptados de Krogh (1973, 1982) e Parrish (1987). O traçador (spike) empregado foi o ${ }^{205} \mathrm{~Pb}$, e o branco total obtido foi da ordem de $10 \mathrm{pg}$. As medições foram efetuadas em espectrômetro de massa multicoletor Finnigan MAT-262. No CPGeo, os valores médios medidos para os padrões NBS-981 e NBS-983 são, respectivamente, de: ${ }^{204} \mathrm{~Pb} /{ }^{206} \mathrm{~Pb}=$ $0,05903 \pm 0,02 \%$ e $0,000368 \pm 3 \% ;{ }^{207} \mathrm{~Pb} /{ }^{206} \mathrm{~Pb}=0,91479 \pm$ $0,01 \%$ e $0,071212 \pm 0,05 \%$ e ${ }^{208} \mathrm{~Pb} /{ }^{206} \mathrm{~Pb}=2,1675 \pm 0,01 \%$ e $0,013617 \pm 0,06 \%$, com variação anual de $1 \sigma$. O fator de correção de fracionamento utilizado para a normalização é de $0,095 \%$ u.m.a. (unidade de massa atômica). Os resultados calculados no programa ISOPLOT 2003 (Ludwig, 2003) com desvios de $2 \sigma$ são apresentados na Tabela 1 . As constantes utilizadas foram as recomendadas por Steiger e Jager (1977): $\lambda\left({ }^{238} \mathrm{U}\right)=1,55125 \cdot 10^{-10} \operatorname{anos}^{-1} \mathrm{e} \lambda\left({ }^{235} \mathrm{U}\right)=9,8485.10^{-10} \operatorname{anos}^{-1}$.

\section{Análises U-Pb (SHRIMP)}

As datações U-Pb (zircões) SHRIMP (Sensitive High Resolution Ion Microprobe) foram executadas dentro do programa de cooperação científica com laboratórios australianos.

Os cristais de zircão foram montados em seções circulares de epoxi com 2,54 cm de diâmetro e $6 \mathrm{~mm}$ de espessura, polidas e metalizadas com película de ouro. Previamente ao 
trabalho de cobertura das seções, foram obtidas imagens de catodoluminescência e de microscópio petrográfico em luz transmitida e refletida, para fins de caracterização dos cristais e escolha dos pontos adequados para as análises.

O equipamento empregado para o trabalho analítico foi o SHRIMP-I e os procedimentos seguiram os descritos em Compston et al. (1984) e Williams (1997). Os padrões usados para a medição das concentrações e das razões isotópicas foram o SL-13 e AS-57. Os erros das contagens são absolutos e referem-se a $1 \sigma$, também utilizado nas idades apresentadas. Os resultados calculados no programa ISOPLOT/Ex, versão 2.10, de Ludwig (2003), observandose as constantes recomendadas pela IUGS (Steiger e Jager, 1977), são fornecidas na Tabela 2 .

\section{Análise $\mathrm{Sm}-\mathrm{Nd}$}

Uma única análise Sm-Nd foi feita em rocha total, seguindo os procedimentos descritos em Sato et al. (1995) e Sato (1998). No CPGeo, os valores médios medidos para os padrões de Nd La Jolla e BCR-1 são, respectivamente, ${ }^{143} \mathrm{Nd} /{ }^{144} \mathrm{Nd}=0,511849 \pm 0,000025$ e $0,512662 \pm 0,000027$ (variação anual de $1 \sigma$ ). Erros máximos medidos das razões ${ }^{143} \mathrm{Nd} /{ }^{144} \mathrm{Nd} \mathrm{e}{ }^{147} \mathrm{Sm} /{ }^{144} \mathrm{Nd}$ em amostras são, respectivamente, menores que $0,004 \%$ e $0,01 \%$, com nível de precisão de $2 \sigma$. As razões isotópicas de $\mathrm{Nd}$ foram obtidas em espectrômetro de massa multicoletor Finnigan MAT-262, enquanto as de Sm em espectrômetro mono-coletor VG-354. O branco total foi da ordem de $0,4 \eta$ g para o $\mathrm{Nd}$ e $0,7 \eta$ g para o Sm. O cálculo da idade modelo foi baseado em De Paolo et al. (1991). As constantes utilizadas foram ${ }^{143} \mathrm{Nd} /{ }^{144} \mathrm{Nd}=$ $0,7219 \mathrm{e}^{143} \mathrm{Nd} /{ }^{144} \mathrm{Nd}(\mathrm{CHUR})_{0}=0,512638,{ }^{147} \mathrm{Sm} /{ }^{144} \mathrm{Nd}$ $(\mathrm{CHUR})_{0}=0,1967 \mathrm{e} \lambda_{147}=6,54.10^{-12}$ anos $^{-1}$. Os resultados analíticos encontram-se na Tabela 3 .

\section{RESULTADOS E DISCUSSÃO}

Os estudos geocronológicos do maciço de Tunas concentraram-se em dois afloramentos: um de sienito e outro de microssienito com textura traquítica (Figura 2).

De modo geral predominam nos dois litotipos cristais de zircão euédricos, bipiramidais, formados por prismas curtos, com relações comprimento $v s$. largura que variam de 3:1 a 1:1 a (Figuras 3 e 4). Eles são translúcidos à luz transmiti$\mathrm{da}$, com destaque para a presença de inclusões e algumas fraturas. Em imagens de catodoluminescência os zircões mostram-se homogêneos, com ausência de zoneamentos e sobrecrescimentos, e contêm inclusões escuras (Figura 5).

As análises U-Pb (ID-TIMS) do sienito (amostra TN-02) foram feitas em quatro frações de zircão (Tabela 1). Quando projetados no diagrama Tera-Wasseburg (Figura 6), os dados apresentam alinhamento médio com idade ${ }^{238} \mathrm{U} /{ }^{206} \mathrm{~Pb}$ de
$82,7 \pm 0,7 \mathrm{Ma}(\mathrm{MSWD}=1,5)$, interpretada como indicativa da época de formação dessas rochas.

Para as análises U-Pb (SHRIMP) do microssienito (amostra VRSS-07) foram selecionados 12 cristais de zircão e analisados 12 pontos (spots), conforme discriminado na Tabela 2. Nesta encontram-se ainda discriminados o hábito dos cristais, a localização do ponto analisado (site) e a característica do cristal em imagem de catodoluminescência. As análises correspondentes às zonas de núcleo e borda dos cristais (Figura 5) apresentam idades concordantes (Tabela 2). No diagrama Tera-Wasserburg (Figura 7), os pontos exibem alinhamento médio com idade ${ }^{238} \mathrm{U} /{ }^{206} \mathrm{~Pb}$ de $84,7 \pm 1,2 \mathrm{Ma}$ $(\mathrm{MSWD}=3,5)$. Acrescente-se que dois dos pontos (spots) analisados (4.1 e 6.1) apresentaram idades pouco superiores

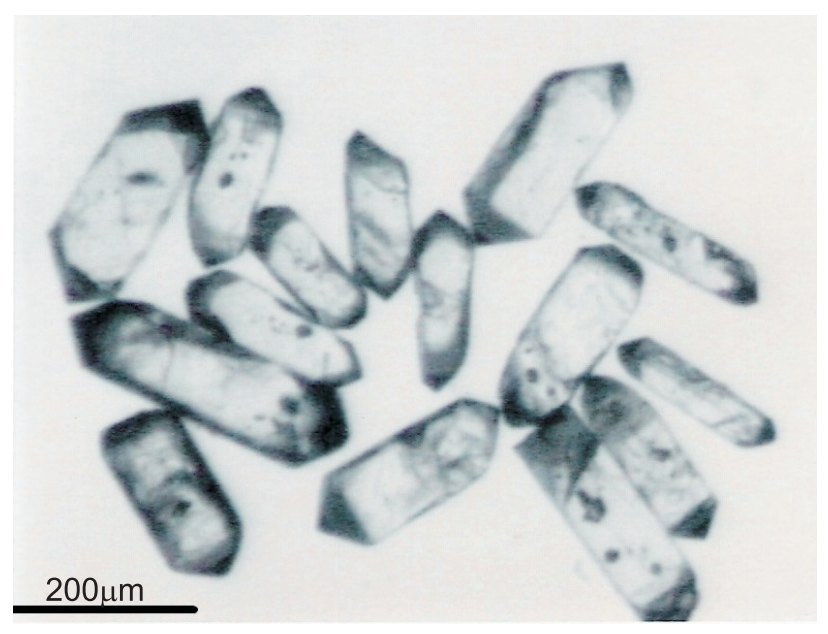

Figura 3. Fotomicrografia de cristais de zircão (relação comprimento vs. largura da ordem de 3:1), fração magnética NM-3 (1), amostra TN-02.

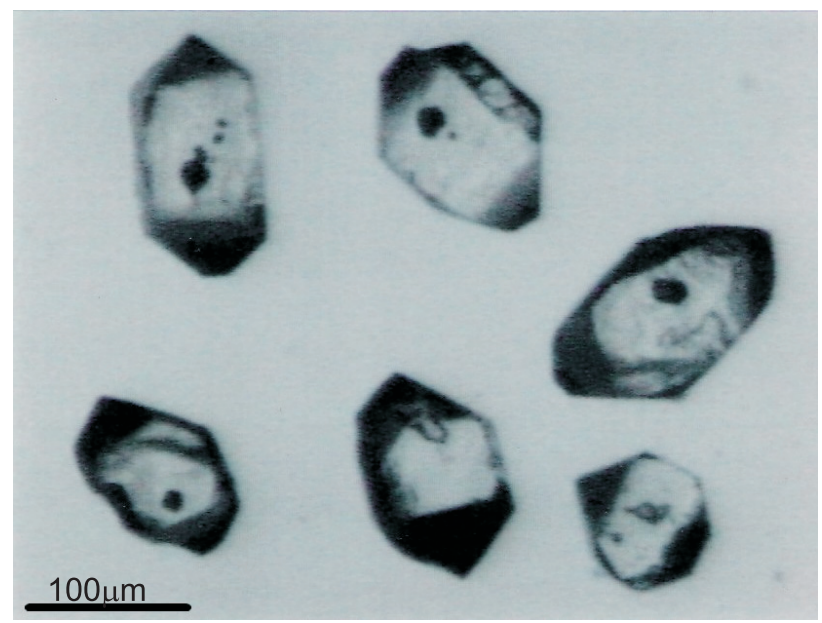

Figura 4. Fotomicrografia de cristais de zircão (relação comprimento vs. largura entre 2:1 e 1:1), fração magnética NM-3 (4), amostra TN-02. 

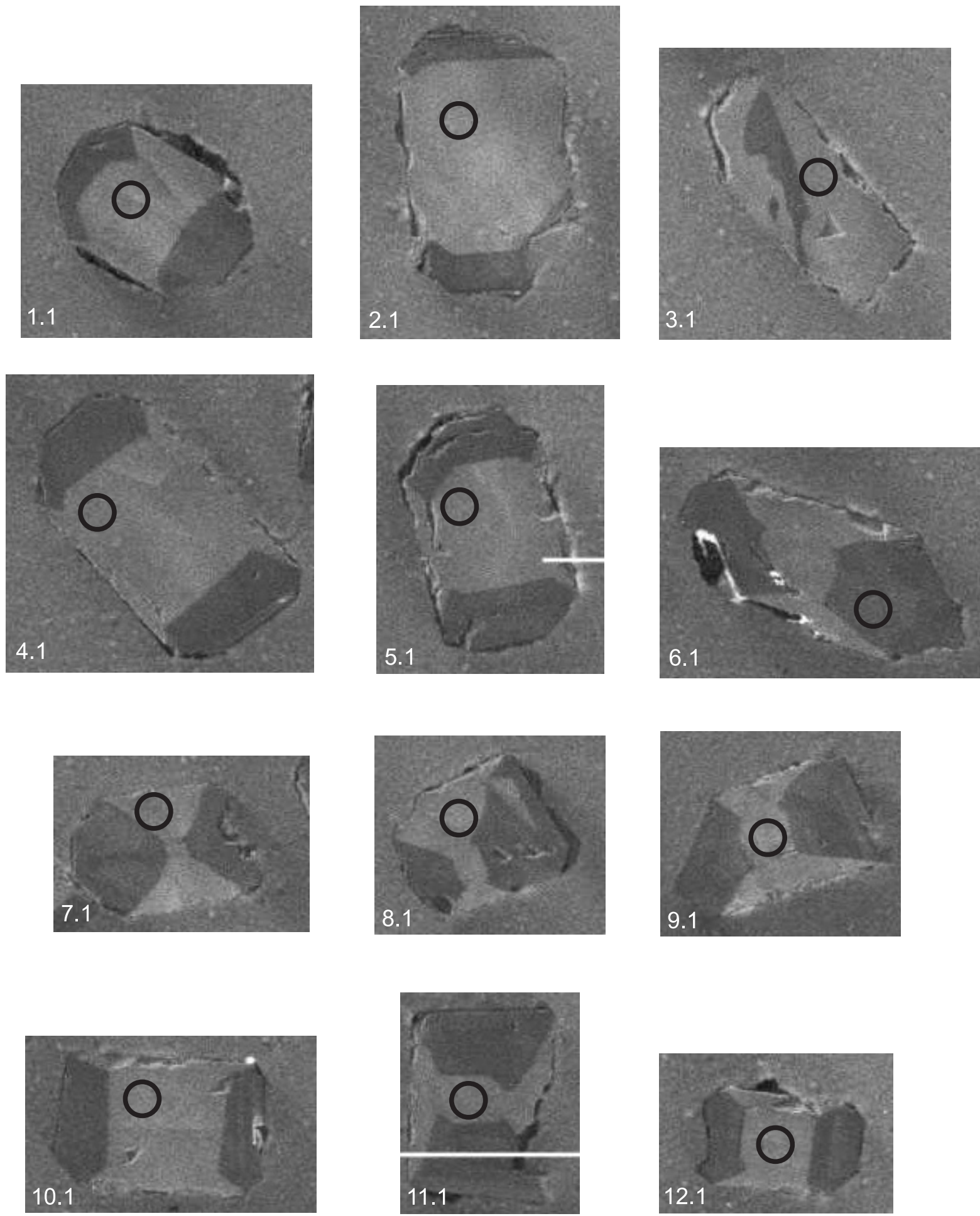

\section{$250 \mu \mathrm{m}$}

Figura 5. Imagens de catodoluminescência de cristais de zircão selecionados para análise por SHRIMP (amostra VRSS-07). Os círculos pretos indicam o local da análise (diâmetro ca. $20 \mu \mathrm{m}$ ). 
$(91,1 \pm 5,1$ e $92,3 \pm 5,1 \mathrm{Ma})$ aos valores médios obtidos e erros relativamente elevados. A idade obtida para o ponto (spot) 8.1 mostra-se, por outro lado, pouco inferior $(81,5 \pm 2,7 \mathrm{Ma})$ aos valores médios obtidos (Tabela 2 e Figura 7).

Os zircões dessas rochas, como mencionado anteriormente, são homogêneos, sem qualquer indicação da presença de heranças isotópicas (núcleos) ou mesmo de zonas de sobrecrescimento. O posicionamento dos pontos de análise pouco acima da curva no diagrama Tera-Wasserburg pode refletir imprecisões devidas a correções de $\mathrm{Pb}$ comum (baixas intensidades, função das idades bastante jovens dessas rochas), padrões empregados (idades superiores, refletindo na normalização) ou mesmo à presença de microinclusões de apatita e de outros minerais nos zircões.

Os valores das idades $\mathrm{U}-\mathrm{Pb}$ obtidas para a rocha sienítica por ID-TIMS $(82,7 \pm 0,7 \mathrm{Ma})$ e microssienítica por SHRIMP (84,7 $\pm 1,2 \mathrm{Ma})$ são muito próximos, com o intervalo 85 - $83 \mathrm{Ma}$ refletindo, portanto, épocas relacionadas à cristalização dos zircões e, conseqüentemente, de formação dessas alcalinas.

Além disso, dispõe-se ainda de uma análise $\mathrm{Sm}-\mathrm{Nd}\left(\mathrm{T}_{\mathrm{DM}}\right)$ para a rocha sienítica (Tabela 3). O valor obtido, de $1019 \mathrm{Ma}$, correspondendo ao final do Mesoproterozóico/início do Neoproteróico, representa a época da derivação do manto dos precursores crustais desses sienitos.

\section{CONSIDERAÇÕES FINAIS}

Idades radiométricas para as diversas ocorrências alcalinas controladas tectonicamente pelo Arco de Ponta Grossa contam como principais fontes de referência biblio-

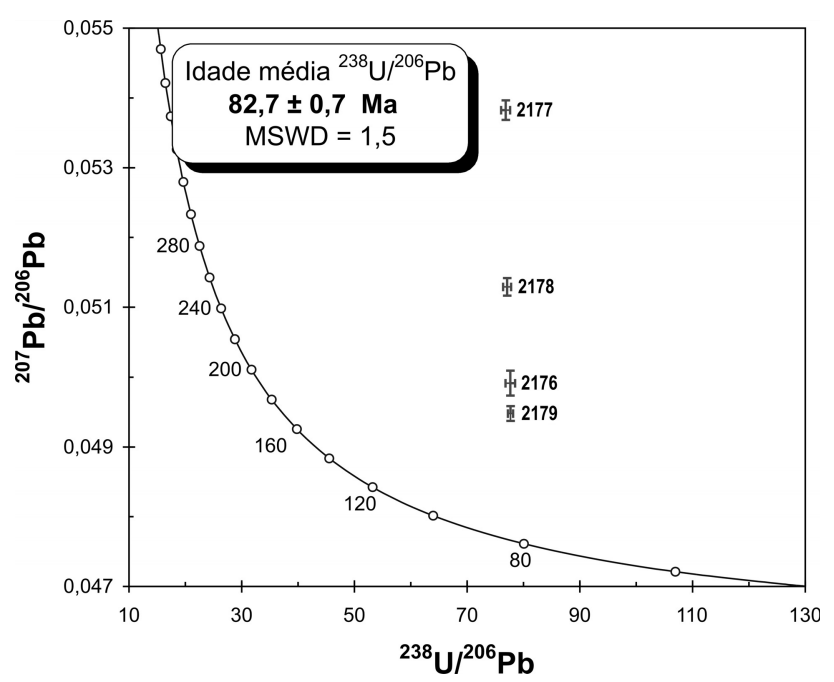

Figura 6. Diagrama Tera-Wasseburg ${ }^{207} \mathrm{~Pb} /{ }^{206} \mathrm{~Pb}$ vs. ${ }^{238} \mathrm{U} /{ }^{206} \mathrm{~Pb}$ em zircões da amostra TN-02. gráfica os estudos pioneiros de Amaral et al. (1967) e Cordani e Hasui (1968), ainda que trabalhos específicos tenham levado à produção de informações adicionais para alguns desses corpos previamente pesquisados. Este é o caso particular de Tunas, que mereceu atenção especial (cf. Gomes et al., 1987) resultando na obtenção de 20 novas datações $\mathrm{K} / \mathrm{Ar}$, seja a partir de concentrados minerais (16 análises: biotita e feldspato alcalino) seja de amostras de rocha total (4 análises). Além disso, a datação pelo método $\mathrm{Rb} / \mathrm{Sr}$ ensejou também a construção de isócrona indicando uma idade de 80,5 Ma para o maciço.

O histograma da Figura 8 (extraído de Gomes et al., 1987) é caracteristicamente unimodal, com a classe modal dominante compreendida no intervalo 80-90 Ma. O valor médio para as análises, excluídas as de Cordani e Hasui (1968), é de 82,2 Ma. Por outro lado, torna-se difícil explicar, à luz dos novos dados, as idades mais antigas fornecidas por esses últimos autores (biotita, sienito, 115,5 Ma; rocha total, gabro, $112,3 \mathrm{Ma})$.

O valor médio para a idade $\mathrm{K}-\mathrm{Ar}$, de 82,2 Ma, obtido a partir de diversos tipos petrográficos intrusivos do maciço é praticamente similar àquele dado pela datação U-Pb (ID-TIMS) em zircão da amostra TN-02, de 82,7 $\pm 0,7 \mathrm{Ma}$, não deixando, assim, qualquer dúvida quanto à época de formação dessas rochas no Cretáceo Superior. Uma vez considerada a idade U-Pb de zircões do microssienito da amostra VRSS-07, de 84,7 $\pm 1,2 \mathrm{Ma}$, chega-se a um intervalo de 85 - 83 Ma para a cristalização daquele mineral.

Como mencionado, Ruberti et al. (2005) incluem as ocorrências alcalinas do Arco de Ponta Grossa em dois conjun-

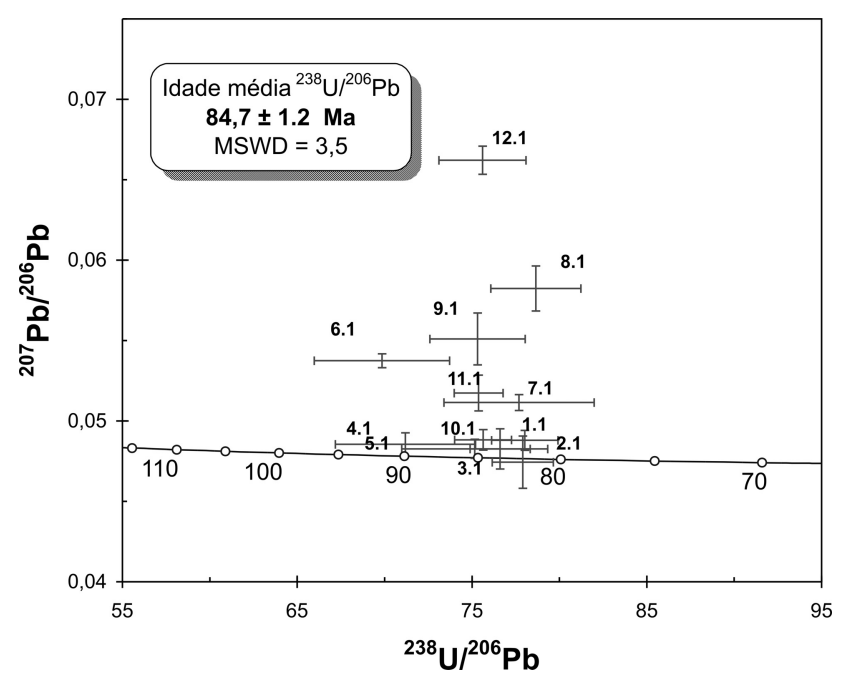

Figura 7. Diagrama Tera-Wasserburg: análises em zircão por SHRIMP (amostra VRSS-07). 

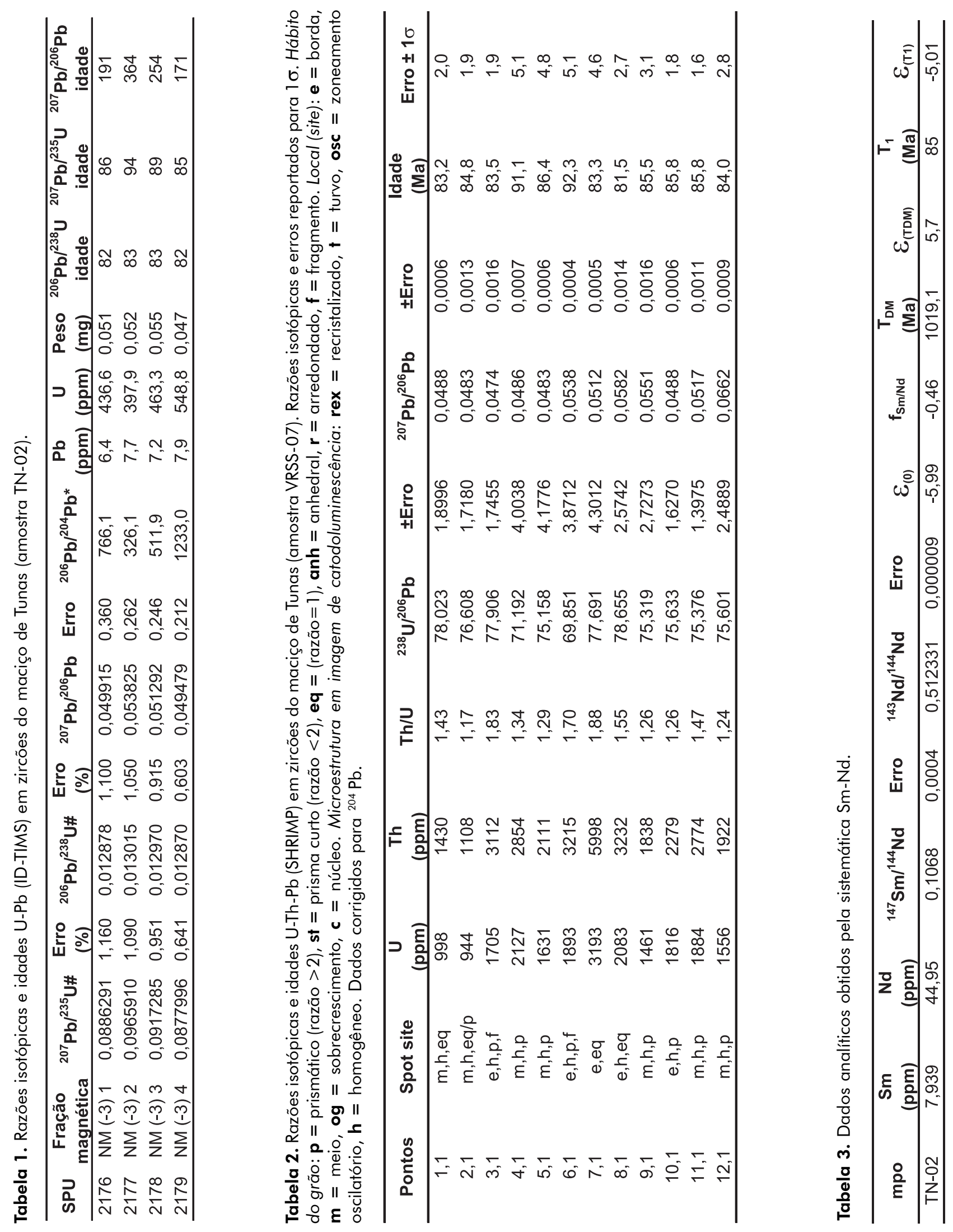


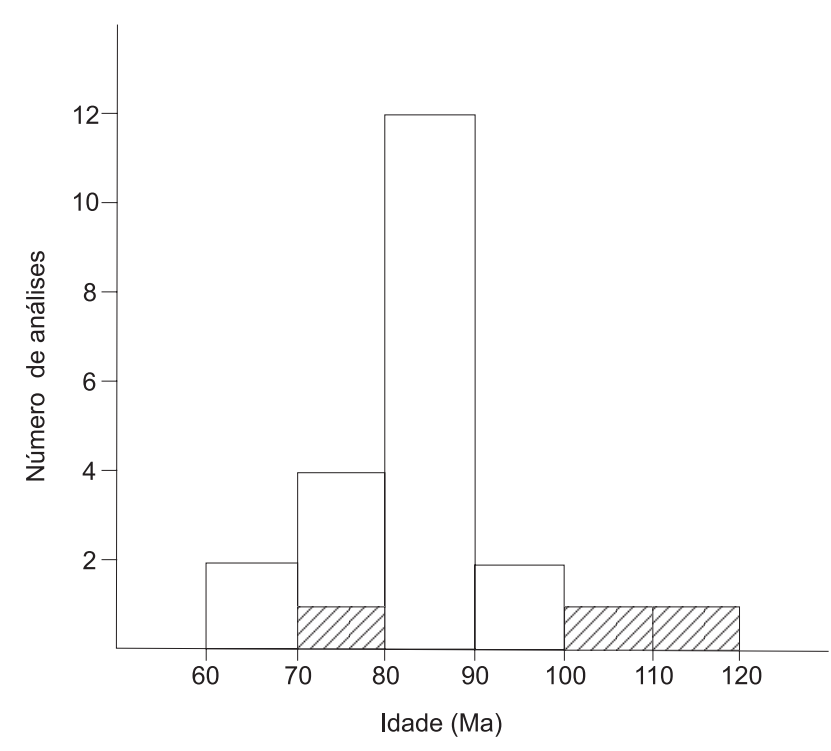

Figura 8. Histograma de idades K-Ar para as rochas de Tunas (extraído de Gomes et al., 1987; dados extraídos de Cordani e Hasui, 1968, representam os campos hachuriados).

tos cronológicos: o primeiro, do Cretáceo Inferior, reunindo os complexos associados tectonicamente ao Lineamento Guapiara; e o segundo, do Cretáceo Superior, ao Lineamento São Jerônimo-Curiúva. Com base em valores de idade modelo $\left(\mathrm{T}_{\mathrm{DM}}\right)$, esses autores procuram relacionar os distintos magmas geradores dessas rochas a dois eventos metassomáticos distintos - levando ao seu enriquecimento em elementos incompatíveis e a razões LREE/HREE elevadas - que teriam ocorrido no manto subcontinental no Proterozóico Superior, respectivamente, a 0,9 Ga e 0,7 Ga. Enquanto as demais intrusões alcalinas do Cretáceo Superior que ocorrem na área (Mato Preto, Itapirapuã e diques) contam com dados coerentes e em maior número de modo a endossar a sugestão acima (idades modelo $\mathrm{T}_{\mathrm{DM}}$ próximas de $0,7 \mathrm{Ga}$ ), a de Tunas dispõe apenas de uma única determinação, $\mathrm{T}_{\mathrm{DM}}=863 \mathrm{Ma}$, com valor abaixo do obtido neste trabalho, de 1019 Ma. Dados adicionais são necessários para melhor caracterizar épocas relativas à diferenciação do manto dos precursores crustais dessas rochas alcalinas do Maciço de Tunas. A idade obtida (1019 Ma), acoplada ao valor calculado para o $\mathcal{E N d}=-5,01$ (tomando como referência uma idade de $85 \mathrm{Ma}$ ), caracteriza um período relativamente longo de vida crustal dos protólitos dessas rochas.

\section{AGRADECIMENTOS}

Estes são devidos à Fapesp (Proc. 01/10714-3) pelo apoio financeiro para a realização desta pesquisa.

\section{REFERÊNCIAS BIBLIOGRÁFICAS}

ALMEIDA, F. F. M. Relações tectônicas das rochas alcalinas mesozóicas da região meridional da plataforma SulAmericana. Revista Brasileira de Geociências, v. 13, p. 139-158, 1983.

ALMEIDA, F. F. M. Distribuição regional e relações tectônicas do magmatismo pós-paleozóico do Brasil. Revista Brasileira de Geociências, v. 16, p. 325-349, 1986.

AMARAL, G.; BUSHEE, J.; CORDANI, U.G.; KAWASHITA, K.; REYNOLDS, J.H. Potassium-argon ages of alkaline rocks from southern Brazil. Geochimica et Cosmochimica Acta, v. 31,p. 117-142, 1967.

BASEI, M.A. S.; SIGAJUNIOR, O.; SATO, K.; SPROESSER, W. M. A metodologia Urânio-Chumbo na Universidade de São Paulo: princípios, aplicações e resultados obtidos. Anais da Academia Brasileira de Ciências, v. 67, p. 221-237, 1995.

COMPSTON, W.; WILLIANS, I.; MYER, C. U-Pb geochronology if zircons from Lunar Breccia 73217 using a sensitive high mass-resolution ion microprobe. Journal of Geophysical Research, v. 89, p. 525-534, 1984.

CORDANI, U. G.; HASUI, Y. Idades K/Ar de rochas alcalinas do primeiro planalto do Estado do Paraná. In: CONGRESSO BRASILEIRO DE GEOLOGIA, 22., 1968, Curitiba. Anais...Belo Horizonte: SBG, 1968. p. 149-153.

DE PAOLO, D. J.; LINN, A. M.; CHUBBERT, G. The continental age distribution: methods of determining mantle separation ages from $\mathrm{Sm}-\mathrm{Nd}$ isotopic data and application to the southwestern Unite States. Journal of Geophysical Research, v. 96, p. 2071-2088, 1991.

FUCK, R. A. Geologia do maciço alcalino de Tunas, Paraná, Brasil. 1972. 82 f. Tese (Doutorado) - Instituto de Geociências, Universidade de São Paulo, São Paulo, 1972.

GOMES, C. B.; CORDANI, U. G. Estudos geocronológicos do maciço alcalino de Itapirapuã, SP, Brasil. Anais da Academia Brasileira de Ciências, v. 37, p. 497-501, 1965.

GOMES, C. B.; BARBIERI, M.; BECCALUVA, L.; BROTZU, P.; CONTE, A.; GARBARINO, C.; MACCIOTTA, G.; MELLUSO, L.; MORBIDELLI, L.; RUBERTI, E.; SCHEIBE, L. F.; TAMURA, R. M.; TRAVERSA, G. Petrological and geochemical studies of alkaline rocks from continental Brazil: 2. The Tunas massif, State of Paraná. Geochimica Brasiliensis, v. 1, n. 2, p. 201-234, 1987. 
KROGH, T. E. Alow contamination method for hydrothermal decomposition of zircon and extraction of $\mathrm{U}$ and $\mathrm{Pb}$ for isotopic age determinations. Geochimica et Cosmochimica Acta, v. 37, n. 3, p. 485-494, 1973.

$\mathrm{KROGH}, \mathrm{T}$. E. Improved accuracy of $\mathrm{U}-\mathrm{Pb}$ zircon ages by the creation of more concordant systems using an air abrasion technique. Geochimica et Cosmochimica Acta, v. 46, n. 5, p. 637-649, 1982.

LUDWIG, K. R. User's manual for Isoplot 3.0: a geochronological toolkit for Microsoft Excel. Berkeley Geochronology Center, 2003. 71 p. (Special Publication, 4).

PARRISH, R. R. An improved micro-capsule for zircon dissolution in $\mathrm{U}-\mathrm{Pb}$ geochronology. Isotope Geosciences, v. 66, p. 99-102, 1987.

RICCOMINI, C.; VELÁZQUEZ, V.F.; GOMES, C. B. Tectonic controls of the mesozoic and cenozoic alkaline magmatism in central-southeastern Brazilian Plataform. In: COMINCHIARAMONTI, P.; GOMES, C. B. Mesozoic to cenozoic alkaline magmatism in the Brazilian Plataform. São Paulo: Edusp/Fapesp, 2005. p. 31-55.

RUBERTI, E.; GOMES, C. B.; COMIN-CHIARAMONTI, P. The alkaline magmatism from the Ponta Grossa Arch. In: COMIN-CHIARAMONTI, P.; GOMES, C. B. Mesozoic to cenozoic alkaline magmatism in the Brazilian Platform. São Paulo: Edusp/Fapesp, 2005. p. 473-521.

SATO, K. Evolução crustal da Plataforma Sul-Americana com base na geoquímica isotópica Sm-Nd. 1998. 299 f. Tese (Doutorado) - Instituto de Geociências, Universidade de São Paulo, São Paulo, 1998.

SATO, K.; TASSINARI, C. C. G.; KAWASHITA, K.; PETRONILHO, L. O método geocronológico Sm-Nd no IGcUSP e suas aplicações. Anais da Academia Brasileira de Ciências, v. 67, p. 315-336, 1995.

SONOKI, I. K.; GARDA, G. M. Idades K/Ar de rochas alcalinas do Brasil meridional e Paraguai oriental: compilação e adaptação às novas constantes de decaimento. Boletim do Instituto de Geociências da USP, Série Científica, São Paulo, v. 19, p. 63-85, 1988.

SPINELLI, F. P.; GOMES, C. B.; VELÁZQUEZ, V. F.; RICCOMINI, C.; COMIN-CHIARAMONTI, P. Considerações petrográficas e geoquímicas sobre a intrusão alcalina de Cananéia, litoral sul de São Paulo. In: CONGRESSO BRASILEIRO DE GEOQUÍMICA, 8.; SIMPÓSIO DE
GEOQUÍMICA DOS PAÍSES DO MERCOSUL, 1., 2001, Curitiba. Anais... Curitiba, 2001. (CD-ROM).

STACEY, J. S.; KRAMERS, D. Aproximation of terrestrial lead isotope evolution by a two stage model. Earth and Planetary Science Letters, v. 26, p. 207-221, 1975.

STEIGER, R. H.; JAGER, E. Subcomission on geochronology: conventions on the use of decay constants in geochronology and cosmochronology. Contributions to the geologic time scale. A.A.P.G. Studies in Geology, v. 6, p. 67-71, 1977.

TREIN, E.; MARINI, O. J.; FUCK, R. A. Rochas alcalinas do primeiro planalto do Estado do Paraná. Boletim Paranaense de Geociências, v. 23-25, p. 325-347, 1967.

ULBRICH, H. .G. J.; GOMES, C. B. Alkaline rocks from continental Brazil. Earth-Science Reviews, v. 17, p. 135-154, 1981.

WILLIAMS, I. S. U-Th-P geochronology by ion microprobe: not just ages but histories. Reviews in Economic Geology, v. 7, p. 1-35, 1997. 